DOI 10.37882/2500-3682.2020.10.20

\title{
ФАКТОРЫ И УСЛОВИЯ ФОРМИРОВАНИЯ ДЕТСКОЙ ЖЕСТОКОСТИ
}

\section{FACTORS AND CONDITIONS FOR THE FORMATION OF CHILD CRUELTY \\ N. Ushanova}

Summary: The article analyzes scientific research devoted to the psychological characteristics of the formation of child cruelty. The article highlights theoretical approaches to the study of the process of cruelty, describes the psychological characteristics of child cruelty. Aggressiveness and sadism, emotional and behavioral components that form the image of a cruel child, psychological characteristics of their relationship and the process of their formation are considered.

Keywords: "cruelty", "aggression", "digitalization", "violence", "rudeness", "egoism", "indifference", "mercy", "hyperactivity".

\author{
Уианова Наталья Викторовна \\ Аспирант, Крымский инженерно-педагогический \\ университет имени Февзи Якубова \\ ushanova_nata@mail.ru
}

Аннотация: В статье анализируются научные исследования, посвященные психологическим особенностям формирования детской жестокости. Выделяются теоретические подходы к изучению процесса жестокости, описываются психологические особенности детской жестокости. Рассматриваются агрессивность и садизм, эмоциональный и поведенческий компоненты, формирующие образ жестокого ребёнка, психологические особенности их взаимосвязи и процесс их формирования.

Ключевые слова: жестокость, агрессия, диджитализация, насилие, грубость, эгоизм, «равнодушие, милосердие, гиперактивность.

силу своего возраста и неразвитого эмоционального интеллекта, проявляет эмоции отлично от взрослого. Согласно исследованиям, жестокость выступает одним из самых распространенных нарушений норм поведения детей, с которыми сталкиваются родители и отдельные специалисты областей педагогики, психологии и социальной работы (воспитатели, учителя, социальные работники, психотерапевты и т.д.). Возрастным диапазоном, в котором возможно наиболее сильное проявление жестокости, принято считать 8-17 лет [2].

Дети склонны испытывать достаточно большой спектр эмоций, который они иногда не могут определить и объяснить, в силу неразвитого эмоционального интеллекта. Достаточно часто в поведении ребенка возможно наблюдать проявления непослушания, раздражительности, капризности, гиперактивности или склонности к конфликтному поведению с применением силы[6]. Для того, чтобы определить, действительно ли ребенок проявляет жестокость, а не транслирует негативные эмоции с целью самозащиты и отстаивания личных границ, необходимо выяснить этимологию понятия «жестокость» [9].

Под «жестокостью» следует понимать такую черту личности, которая определяется как безразличие к страданиям живых существ или стремление навредить и причинить страдания другим. Итак, исходя из данного определения, мы понимаем, что проявление жестокости человеком нельзя оправдать защитой своих личных границ, скорее, наоборот, это грубое нарушение границ других людей, которое выражается в физическом и моральном насилии и причиняет другому значительный вред[8]. 
Когда мы говорим об агрессивном поведении, следует отметить две его основные формы:

1. Непатологическую, которой характерна незначительная, не слишком грубая выраженность поведенческих нарушений, которая может быть скомпенсирована при попадании ребенка в благоприятные для него условия.

2. Патологическую, которой присущи качественные изменения в характере ребенка, насильственные проявления в его поведении, возникновение озлобленных реакций на внешние раздражители, стремление к мести и садизму, проявление жестокости к кому-либо.

Согласно возрастной периодике, у мальчиков и у девочек отмечаются несколько пиковых периодов, при которых проявление жестокости может быть максимально проявленным. В основном, этот период затрагивает предподростковый и подростковый возраст: мальчики достигают пика агрессивности и жестокости, как правило, в 12 лет и в 14-16 лет; девочки - 11 лет и 13 лет. Пиковые скачки проявлений жестокости и агрессии, как видно, связаны с периодом пубертата - полового созревания подростков, при котором происходит гормональный всплеск, а контроль и регуляция личного поведения снижается до минимального уровня. При этом, жесткость не оправдана гормональными изменениями в организме ребенка, это, скорее, сопутствующий, усиливающий агрессивность, фактор, нежели первопричина соответствующего поведения.

Различают детскую жесткость двух видов - вербальную и физическую. Под вербальной жестокостью понимают косвенные проявление в виде жалоб на кого-либо, желание передразнить, оскорбить и прямые проявления жестокости в виде серьезных оскорблений, угроз расправой. Физическая косвенная жестокость проявляется в форме преднамеренного желания порчи чужого имущества: разорвать одежду другого, разбить его посуду, сломать игрушки и т.д., В целом, при косвенной физической жестокости, вред наносится личным вещам другого, что может достаточно его ранить, т.к. вещь может быть любима и значима[15]. При физической прямой агрессии наблюдается уже физическое насилие, направленное на другое лицо: провоцирование и совершение драки, избиение, плевки и кусание, т.е. все то, что нарушает физические границы другого человека, причиняет ему боль и вредит жизни и здоровью. Стоит отметить, что данное жестокое поведение преднамеренное, активное и инициативное и именно поэтому может быть опасно для социума, в котором находится ребенок. Выраженность компонентов агрессивности показывает, что юноши преобладают в численности в проявлениях прямой физической агрессии, а девочкам более присуща жестокость косвенная (как вербальная, так и физическая) [11]
Как и у взрослых, у детей наблюдается жестокость в следующих своих формах: целенаправленная и враждебная. Целенаправленная жестокость проявляется в ситуациях, когда ребенку необходимо адаптироваться к внешним условиям. Здесь срабатывает инстинкт, который заложен в «рептильном» мозге человека - «бей или беги» и ребенок выбирает агрессию и жестокость для того, чтобы добиться своей цели, удовлетворить какиелибо возникающие желания. В целом, данный механизм, отчасти, имеет и положительные последствия, т.к. стимулирует ребенка конкурировать, отстаивать свое место в окружающем мире, транслировать личные интересы и права, учит полагаться на себя в различных ситуациях, приобретать навыки и развивать имеющиеся способности. Но, это возможно лишь тогда, когда эти механизмы не направлены на других людей, с целью причинения им вреда. Вторая форма проявления жестокости не просто основывается на злобных, агрессивных и враждебных проявлениях в поведении личности, но трансформируется в целенаправленное желание причинить вред другой личности (как физический, так и моральный) и получить от этого удовлетворение. Зачастую, результат проявления враждебной жестокости проявлен в виде конфликтов, драк, издевательств, что еще больше укореняет жестокость в структуре личности ребенка и ведет к снижению его же адаптивных возможностей [5].

Для того, чтобы распознать наличие черт жестокости в личности ребенка, необходимо проводить диагностику его агрессивности. Наибольший диагностический эффект возможен при условии работы квалифицированного психолога. Обращения к специалисту требуют случаи, которые предполагают наличие очевидных проявлений у ребенка следующих особенностей поведения:

1. Ребенок часто теряет над собой контроль, ему трудно совладать с негативными эмоциями, он не может найти им объяснения.

2. Ребенок достаточно часто провоцирует конфликтные ситуации со сверстниками и даже взрослыми, применяет физическое насилие в процессе конфликтов.

3. Ребенок преднамеренно отказывается от выполнения просьб взрослых, игнорирует установленные границы.

4. Ребенок склонен обвинять в своем плохом настроении и поведении других людей и не берет ответственности за личные действия на себя.

5. Ребенок слишком мнителен, может проявлять неуверенность в себе, а также зависть по отношению к сверстникам.

6. Ребенок намеренно причиняет физическую боль другим людям (в особенности, другим детям) и животным.

7. Ребенок проявляет очень низкий уровень сочувствия во взаимоотношениях с другими людьми и по отношению к животным. 
8. Ребенок проявляет симптомы невралгии (рассеянность внимания, неустойчивость в запоминании, низкий уровень оперативной памяти и т.д.).

9. Ребенок не может спрогнозировать последствия, которые повлекут его действия и зацикливается эмоционально на проблемных ситуациях.

Человек - социальное существо, которое нуждается во взаимодействии с себе подобными, а также стремится к удовлетворению базовых потребностей в любви, дружбе и безопасности. Жестокость не возникает безосновательно, ребенок не рождается жестоким или агрессивным, но может стать таковым, вследствие влияния определенных факторов, раскрытых в данной работе.

\section{1. Семья как первопричина жестокости ребенка.}

Bce, чем напитан ребенок, что он транслирует и как видит и понимает окружающий мир - произрастает из семьи, в которой он живет. Отношения членов семьи, их взаимодействие транслирует ребенку ценности, которыми он будет руководствоваться в течение своей жизни. Существует значительное количество факторов, которые сформированы в пределах семьи и имеют прямое влияние на степень развития жестокости у ребенка [12]. Самыми распространенными являются следующие:

- отсутствие сплоченности всех членов семьи, что ребенок воспринимает как ситуацию небезопасности;

- отсутствие эмоциональной близости между членами семьи, в особенности - между родителем и ребенком;

- повышенный уровень конфликтности в семье (как между взрослыми, так и во взаимоотношениях взрослых и детей);

- негативный характер взаимоотношений между детьми в рамках одной семьи;

- жестокость и агрессивность во взаимоотношениях родителей;

- отсутствие адекватного стиля воспитания, наличие гиперопеки или, напротив, гипоопеки над ребенком.

Отдельно стоит отметить особенности, которые наблюдаются в семьях, дети которых имеют проявления жестокости в поведении [10]:

1. Эмоциональная разобщенность между членами семьи приводит к постепенному снижению уровня привязанности. Родители в таких семьях не имеют общих ценностей или не разделяют ценностей детей. В последствии это приводит к возникновению негативных эмоций по отношению друг к другу. Ребенок научается жить в постоянной небезопасной атмосфере, не чувствует безопасной атмосферы в семье, приобретает паттерны поведения готовности к защите в каждый момент вре- мени, поэтому его психика находится в состоянии мобилизации, что стимулирует ребенка всегда быть готовым к «нападению».

2. Агрессивное поведение с элементами жестокости, которое транслируется в семье, воспринимается ребенком как норма и формирует его отношение к окружающим людям не только в детском возрасте, но и закрепляется во взрослой жизни. Дети, которые испытывали семейное насилие, в большинстве случаев закрепляют данный паттерн и транслируют его на окружающий социум. При этом, они не имею вариативности решения конфликтных ситуаций, кроме как тех моделей, которые были получены ими из семейных сценариев. Зачастую можно встретить ситуации, в которых родители поощряют проявления жестокости в своих детях, культивируя тем самым отрицательное поведение (например, отцы склонны поощрять в своих сыновьях агрессивность и жестокость, тем самым пытаясь воспитать настоящего мужчину). Ребенок, который воспринимает родительскую фигуру как безусловного авторитета, несомненно будет стремиться соответствовать таким ожиданиям значимого для него человека, что, опять же, закрепить такую модель поведению, как единственно верную.

3. Родители в рамках одной семьи применяют модели воспитания детей, которые противоречат друг другу. В результате, требования, которые предъявляются к ребенку, могут быть диаметрально противоположными, что вызывает у ребенка чувство дестабилизации, непонимания и тревоги. На основании этого могут сформироваться невротические проявления, а также ребенок закрепит модель такого оппозиционного и вызывающего поведения, которое будет транслировать на окружающий социум, но уже посредством личных проявлений в поведении.

4. Для семьи характерны методы воспитания, предполагающие угрозы, физические наказания, запреты и лишения определенных привилегий ребенка, жесткие ограничения, полное отсутствие поощрительной системы, намеренная изоляция ребенка в воспитательных целях, а также осознанное лишения ребенка заботы, любви и общения в случае его ошибки или проступка. Такие недолюбленные дети растут в атмосфере страха, который, впоследствии, порождает гнев, агрессию и жестокость, ребенок проявляет асоциальное поведение и совершает аморальные поступки.

\section{2. СМИ как фактор формирования жестокости у ребенка [14].}

Современное информационное поле стремительным потоком обрушивается на человека. И если взрослый, 
обладая критическим мышлением, способен отсеять ненужную и вредную информацию, то ребенок не в силах с эти справится по причине отсутствия или недостаточной развитости этого критического фильтра. Так, СМИ, в особенности телевидение, формирует агрессивное и жестокое поведение детей, посредством телепередач, а также художественных фильмов, которые демонстрируют откровенные сцены насилия, убийства и издевательств. Наиболее опасными для психики детей являются триллеры и фильмы ужасов, которые могут травмировать психику ребенка и спровоцировать у него психические расстройства.

\section{3. Сеть «Интернет» как источник жестокого поведения ребенка}

Нынешнюю жизнь современных детей достаточно сложно вообразить без пользования интернетом. Ребенок достаточно умело использует гаджет с младенческого возраста. Естественно, невозможно оградить ребенка от интернета полностью, но это стоит делать частично, т.к. бесконтрольное пользование интернетом является первопричиной порождения жестокости у детей. Социальные сети, в которых открыто демонстрируется абсолютно разный, в том числе и находящийся под запретом для лиц, младше 18 лет, контент, жестокие игры, с элементами насилия, убийств, крови, фильмы, которые транслируют сцены насилия - все это в открытом доступе ребенок может получить в любой момент. Но, по данным социологических групп, наибольшее влияние на формирование жестокости детей, является наличие в интернете жестоких видеороликов со сценами насилия над животными, детьми, сексуального насилия и домогательств, избиений, драк и т.д. Ребенок, который имеет доступ к просмотру такого контента, воспринимает его как руководство к действию, т.к. если это безнаказанно делают другие, значит это возможно делать и ему. Наиболее опасным в данном случае является тот факт, что такие видеоролики подаются под видом «современной жизни», независимости, силы. Иными словами, модно проявлять себя так, а не иначе, проявить силу, поставить кого-либо «на место», показать, «кто здесь главный». Ребенок понимает, что исключительно посредством подобного поведения он может завоевать авторитет среди сверстников и быть принятым в компанию, не стать в ней «белой вороной». Огромное количество детских и подростковых убийств происходит именно потому, что ребенок следовал за сверстниками, не хотел показаться иным, выделиться[15].

Итак, тема детской жестокости требует глубокого и детального изучения, т.к. из жестокого ребенка вырастает жестокий взрослый, который может быть потенциально опасен для общества. Именно поэтому работа со специалистами помогающих профессий необходима как для детей, демонстрирующих жестокость в своих проявлениях, так и для их семей, в целом.

1. Теоретический анализ публикаций по теме детской жестокости показал, что на данном этапе развития научной мысли существует множество факторов формирования деткой жестокости.

2. Проанализировав публикации и литературу, мы видим, что тема детской жестокости важная, распространенная и актуальная. Жестокость среди детей растет с огромной скоростью.

3. Согласно многочисленным исследованиям, сейчас проявления детской жестокости являются одной из наиболее распространенных форм нарушения поведения, с которыми приходится иметь дело взрослым - родителям и педагогам.

4. Исследователи выделяют следующие факторы жестокого поведения детей: биологически обусловленные (особенности нервной системы), психологические (направленность личности, мотивация, дефекты характера, наличие установок на девиантное поведение, неудовлетворенность базовых потребностей), социальные (нарушение процесса социализации в семье, нарушение направленной деятельности).

\section{ЛИТЕРАТУРА}

1. Андрюшина Л.О. Психологическая профилактика агрессивного поведений школьников-подростков: Дис. ... канд. психол. наук. - Тверь, 2003. - 202 с.

2. Воспитание трудного ребенка: дети с девиантным поведением /под ред. М.И. Рожкова.- М.: Владос, 2006. -239 с.

3. Воспитание экологической культуры у детей и подростков. - М.: Педагогическое общество России, 2013. - 64 с.

4. Жуина Д.В. Особенности тревожности младших школьников и подростков из неполных семей / Д.В. Жуина, Р.Р. Юсупова// Евразийский Союз Ученых. - 2015. - №11-2 (20). - С. 116-117. - Электрон. копия доступна на сайте науч. электрон. 6-ки Киберленинка. URL: https://cyberleninka.ru/article/n/ osobennosti-trevozhnosti-mladshih-shkolnikov-i-podrostkov-iz-nepolnyh-semey (дата обращения: 8.06.2020).

5. Заостровцева, М.Н. Агрессивность дошкольников: коррекция поведения : пособие / М.Н. Заостровцева, Н.В. Перешеина. - Москва : (фера, 2006. - 112

6. Иванова И.В. Влияние переживаний на развитие личностной идентичности у детей старшего дошкольного и младшего школьного возраста.- М.: Просвещение, 2001. - 265 с.

7. Козырева Е.В. Дифференциально-психологические аспекты ауто- и гетероагрессивности в подростково-юношеском возрасте и в период ранней взрослости: Дис. канд. психол. наук. - СПб., 2006. - 154 с.

8. Лачугина Ю.Н. Агрессивность В структуре личности и профессиональной деятельности руководителя: Дис. ... канд. психол. наук. - Ульяновск, 2003. - 162 с. 
9. Можгинский, Ю.Б. Агрессивность детей и подростков. Распознавание, лечение, профилактика / Ю.Б. Можгинский. - М.: Когито-Центр, 2006. - 184 с.

10. Музыченко Г.Ф. Проективная методика «Несуществующее животное». - СПб.: Речь, 2012. - 560 с.

11. Суворова 0.В. Влияние родительского общения и структуры семьи на самооценку младшего школьника / О.В. Суворова, С.Н. Сорокоумова, И.В. Ивенских // Педагогика и психология образования. - 2017. - № 3. - С. 179-188 - Электрон. копия доступна на сайте науч. электрон. 6-ки Kиберленинка. URL: http:// cyberleninka.ru/article/n/vliyanie-roditelskogo-obscheniya-i-struktury-semi-na-samootsenku-mladshego-shkolnika... (дата 0бращения: 8.06.2020).

12. Фурманов, И.А. Агрессия и насилие. Диагностика, профилактика и коррекция / И.А. Фурманов. - М.: Речь, 2007. - 480 с.

13. Чижова С.Ю., Калинина 0.В. Детская агрессивность. - Ярославль. 2005. 89-91 с.

14. Шипунова Т.В. Агрессия и насилие как элементы социальной реальности // СоцИс. - 2002. - № 5. - С.23-25.

15. Щербинина, Ю.В. Вербальная агрессия / Ю.В. Щербинина. - М.: ЛКИ, 2008. - 360 с.

16. Яньшин П.В. Практикум по клинической психологии. Методы исследования личности. - СПб: Питер, 2004. - 336 с: ил. - (Серия «Практикум по психологии»).

(c) Ушанова Наталья Викторовна (ushanova_nata@mail.ru).

Журнал «Современная наука: актуальные проблемы теории и практики»

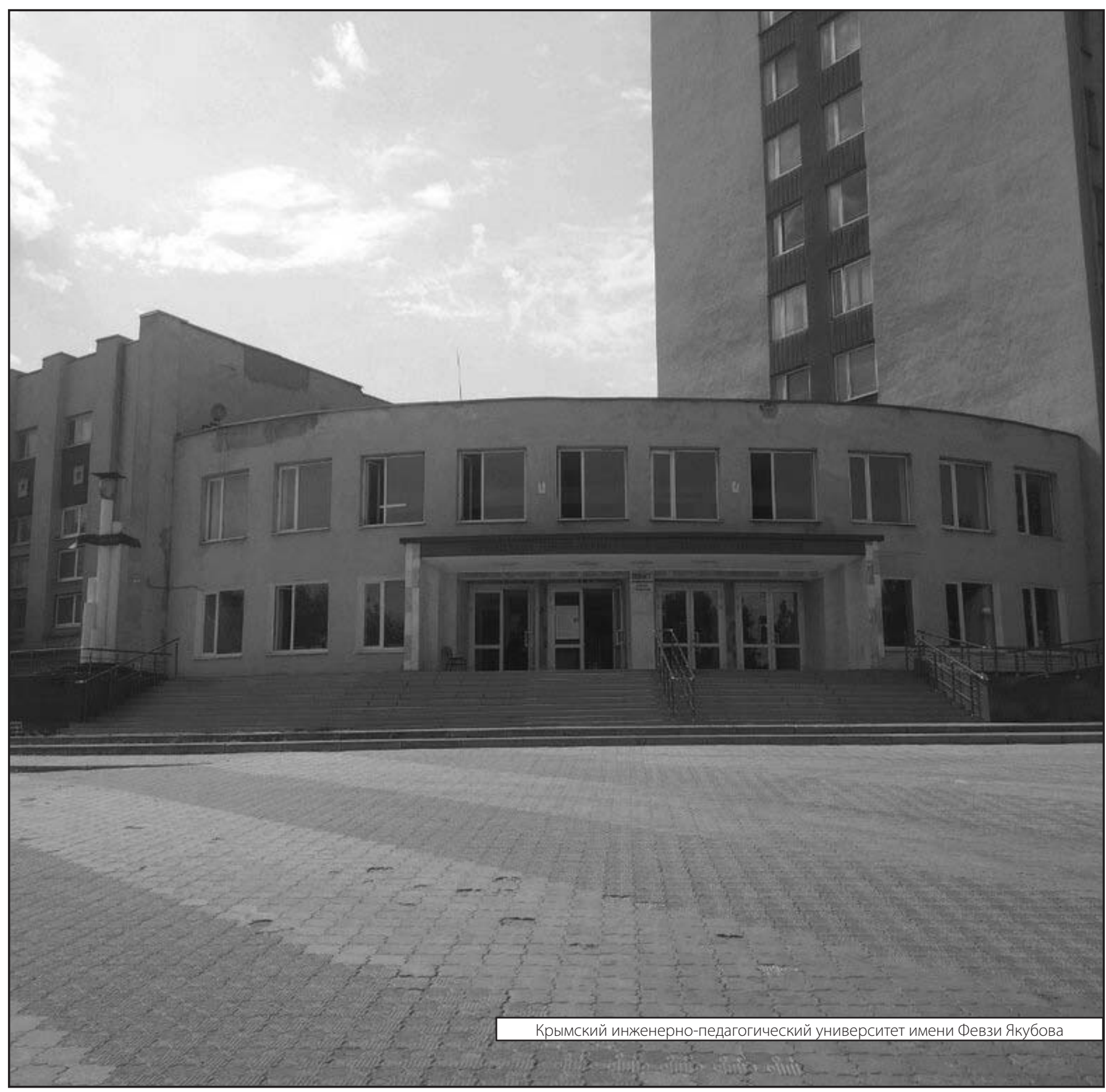

